the local population. Less than $50 \%$ planned their pregnancy, because of failed oral contraceptive, $71 \%$ were still having seizures, and 157 of 252 questioned admitted incomplete drug compliance. A follow-up of 105 infants in the Northern English cohort identified 23 developmentally delayed infants, 7 severe.

In Nebraska, a susceptibility gene for valproate-induced anomalies in the mouse has been identified, syntenic with the short arm of human chromosome 16 . (Finnell RH, Burn J. Effect of anti-epileptic drugs on intrauterine growth. Lancet November 4, 2000;356:1537). (Respond: Dr Richard H Finnell, Center for Human Molecular Genetics, University of Nebraska Medical Center, Omaha, Nebraska 68198, USA; Dr John Burn, Northern Region Genetics Service, University of Newcastle upon Tyne, Newcastle upon Tyne, UK).

COMMENT. This review is important because the teratogenic potential of newly approved antiepileptic drugs has not yet been determined, and their introduction has not replaced that of conventional therapies.

\title{
MICROCEPHALY AND EPILEPSY
}

The prevalence of epilepsy and learning disability among various types of microcephaly was determined in a study of 66 cases (age range from 2 to 19 years) at the National Research Centre, Cairo, Egypt, and the Department of Human Genetics and Teratology, National Center for Epidemiology, Budapest, Hungary. Microcephaly was classified according to pathogenesis and etiology as isolated (IMC) or multiple (MMC) and primary (PMC) or secondary (SMC). Using Hungarian growth charts, a maximal occipitofrontal head circumference of 2 or more standard deviations below the mean of age and sex-matched participants was accepted as the definition of MC. Cases of craniosynostosis and Down syndrome were excluded. The overall prevalence of epilepsy (mainly generalized tonicclonic) was $41 \%$. It was significantly higher among males. SMC showed a higher incidence of epilepsy and lower IQ when compared with PMC. Learning disability (LD) occurred in $94 \%$, severe in $44 \%$. Severity of epilepsy was correlated inversely with IQ and directly with degree of LD. Participants with MMC due to teratogens (fetal alcohol syndrome) showed a low growth rate. (Abdel-Salem GMH, Halasz AA, Czeizel AE. Association of epilepsy with different groups of microcephaly. Dev Med Child Neurol Nov 2000;42:760-767). (Respond: Dr Ghada MH Abdel-Salam, Department of Human Genetics, National Research Centre, Tahrir, Dokki, Cairo, Egypt).

COMMENT. Primary microcephaly, resulting from anomalous development in the first 7 months of gestation, may be genetic (autosomal recessive), a chromosomal disorder, or caused by various environmental factors (irradiation, in utero infection, chemical). Secondary microcephaly, due to an insult incurred in the last 2 months of gestation or perinatally, may be infectious, traumatic, metabolic, or anoxic in origin (Menkes JH. Textbook of Child Neurology). Almost all will be mentally retarded or have learning disabilities, and $40 \%$ will suffer from epilepsy.

The pathological findings in primary microcephaly, as described in Greenfield JG (Neuropathology) include a small brain, weighing 500 to $600 \mathrm{~g}$ at birth, a disproportionately large cerebellum, basal ganglia, and corpus callosum, simple cerebral convolutional pattern with broad gyri, and typical columnar grouping of nerve cells, histologically. Myelination of the central white matter and long fiber tracts is normal: 